\title{
Hypertrophic osteoarthropathy in adults with cystic fibrosis
}

\author{
M. A. MA T THA Y, R.A. MA T THA Y, D. M. M I L L S, \\ S. LAKSHM INARA YAN, and E. COTTON \\ Department of Medicine, Pulmonary and Arthritis Divisions, and the Department of Pediatrics, \\ University of Colorado Medical Center, Denver, Colorado, USA
}

\begin{abstract}
Matthay, M. A., Matthay, R. A., Mills, D. M., Lakshminarayan, S., and Cotton, E. (1976). Thorax, 31, 572-575. Hypertrophic osteoarthropathy in adults with cystic fibrosis. Three adult patients with cystic fibrosis presented with arthralgia, and investigation for the usual causes of arthritis proved negative. Radiographs of long bones revealed periostitis and new bone formation characteristic of hypertrophic osteoarthropathy. Symptomatic improvement occurred after analgesic and anti-inflammatory therapy. In patients with cystic fibrosis and bone or joint pain, the diagnosis of hypertrophic osteoarthropathy should be considered and long bone radiographs obtained.
\end{abstract}

A 24-year-old man with cystic fibrosis presented to the University of Colorado Medical Center with arthralgia and joint effusions of unknown cause. Initial evaluation, including joint fluid analysis, failed to yield a diagnosis. Long bone radiographs revealed typical changes of hypertrophic osteoarthropathy, a syndrome characterized by ossifying periostitis of long bones, arthritis, and clubbing (Bamberger, 1889; Hammarsten and O'Leary, 1957). A delay in diagnosis occurred due to lack of awareness of an association between hypertrophic osteoarthropathy and cystic fibrosis in adults. Subsequently, two more adults with cystic fibrosis have been diagnosed as having hypertrophic osteoarthropathy. These three cases are described in detail to emphasize this association.

\section{CASE REPORTS}

PATIENT 1 A 24-year-old man, in whom a diagnosis of cystic fibrosis had been made at the age of 3 years, was admitted to the hospital in January 1974 with a three-week history of arthralgia in the ankles, knees, and wrists and bilateral knee swelling. His past history included progressive dyspnoea, productive cough, recurrent pneumonitis, chronic diarrhoea, and liver disease due to cystic fibrosis. Two years before

${ }^{1}$ Normal values for adults less than $70 \mathrm{mEq} / 1$ (Jones, Steige, and Logan, 1970) admission he had an upper gastrointestinal haemorrhage due to oesophageal varices.

The blood pressure was $118 / 78 \mathrm{mmHg}$, pulse $\frac{0}{\varnothing}$ 90 , respirations 28 , and temperature $37 \cdot 3^{\circ} \mathrm{C}$. Clubbing of the toes and fingers with tenderness $\overrightarrow{\vec{B}}$ of the ankles, knees, and wrists was present. Effusions were noted in both knees. Chest examination revealed diffuse rhonchi and basal crepitations. A loud pulmonary second sound and a right ventricular lift were found, but the jugular venous pressure was not raised. The liver $x$ was enlarged with a span of $13 \mathrm{~cm}$; the spleen was palpable $3 \mathrm{~cm}$ below the left costal margin. The sweat chloride was $100 \mathrm{mEq} / \mathbf{1}^{1}$. Clear yellow fluido aspirated from the right knee revealed $850^{\circ}$ $\mathrm{WBC} / \mathrm{mm}^{3}$ (all mononuclear cells) with a good? mucin clot but no crystals and no growth on cul- $\frac{D}{8}$ ture. Arterial blood gases while breathing ambient air were $\mathrm{pH} 7 \cdot 45, \mathrm{PCO}_{2} 31 \mathrm{mmHg}$ (Denver normaln 34-38), $\mathrm{PO}_{2} 60 \mathrm{mmHg}$ (Denver normal 65-75) Pulmonary function tests revealed a moderate obstructive defect. An electrocardiogram showedw right axis deviation and right atrial and right ventricular enlargement. Alkaline phosphatase was $555 \mathrm{IU} / 1$ (normal less than 280), serume aspartate aminotransferase $13 \mathrm{IU} / 1$ (normal 6-21) $;$ and total bilirubin $0.3 \mathrm{mg} / 100 \mathrm{ml}$. A chest radiograph demonstrated diffuse interstitial anc nodular infiltrates (Fig. 1). Radiographs of the? extremities showed periosteal elevation in the fifth metatarsal bilaterally and periosteal elevation an 


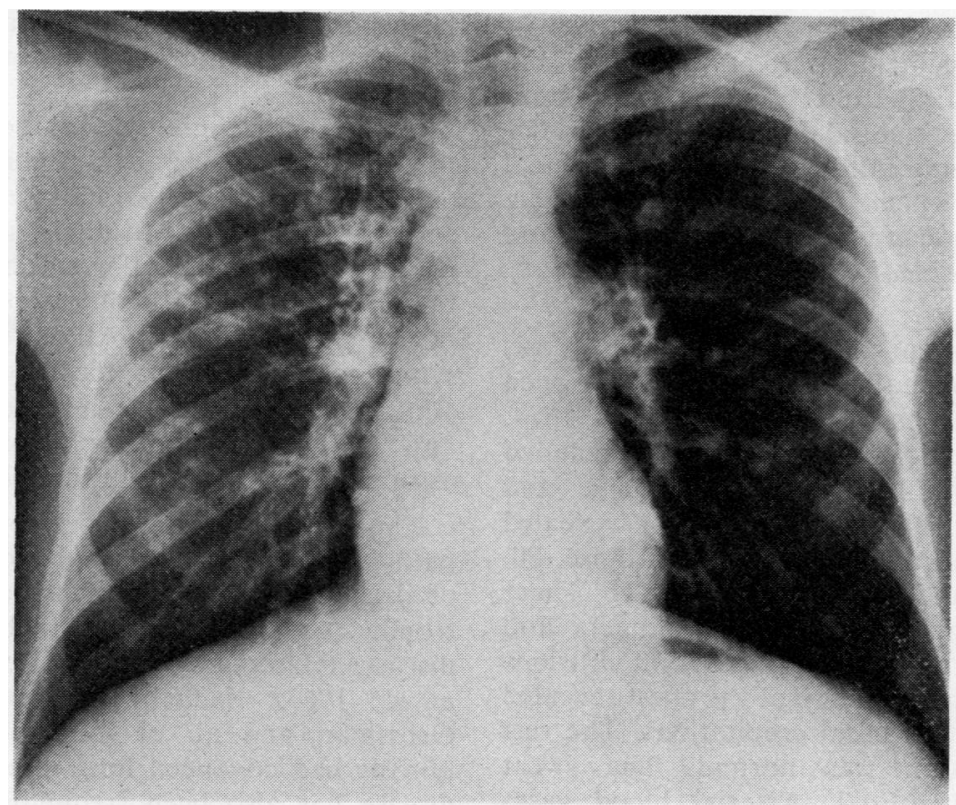

FIG. 1. Chest radiograph of patient 1 showing diffuse interstitial and nodular infiltrates.

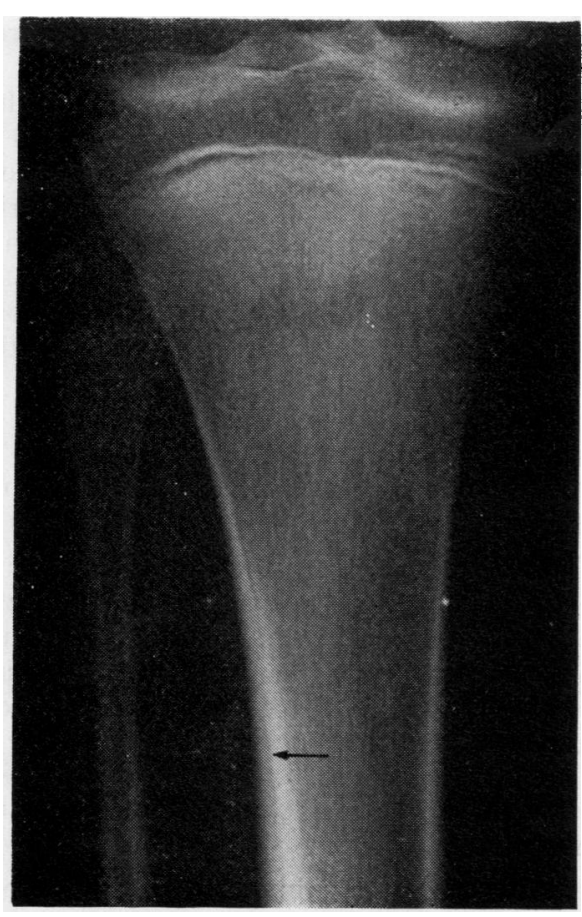

FIG. 2. Radiograph of left tibia and fibula of patient 1 demonstrating periosteal elevation and new bone formation (arrow). new bone formation in the left tibia (Fig. 2). The joint pains and knee effusions resolved after treatment for four weeks with acetominophen and indomethacin. Although the radiographic abnormalities of the bones persist, the arthralgia has not recurred.

PATIENT 2 A 23-year-old man with cystic fibrosis diagnosed at the age of 5 years was admitted to the hospital in April 1974 with painful knees and ankles for the previous two months. Manifestations of the disease before this admission included dyspnoea at rest with a chronic productive cough, recurrent pneumonia, and chronic diarrhoea. The blood pressure was $120 / 80 \mathrm{mmHg}$, pulse 92 , respirations 24 , and temperature $37 \cdot 4^{\circ} \mathrm{C}$. There was finger and toe clubbing with warmth and tenderness over the ankles and knees bilaterally, but no joint effusions were present. Examination of the chest revealed diffuse bilateral crepitations and the cardiac examination was within normal limits with the exception of a loud pulmonary component of the second sound. The rest of the examination was normal. The sweat chloride was $118 \mathrm{mEq} / 1$. Arterial blood gases while breathing ambient air were $\mathrm{pH} \mathrm{7.43, \textrm {PCO } _ { 2 }}$ $40 \mathrm{mmHg}$, and $\mathrm{Po}_{2} 40 \mathrm{mmHg}$. Pulmonary function tests showed a severe obstructive defect. 
Right axis deviation and right atrial and right ventricular enlargement were present on the electrocardiogram. The chest radiograph demonstrated bilateral interstitial infiltrates, and radiographs of the extremities showed periosteal elevation and new bone formation in the tibiae. The patient was treated with acetominophen and the bone pain subsided with no recurrence.

PATIENT 3 A 21-year-old man with a diagnosis of cystic fibrosis since the age of 4 years developed bilateral ankle and knee pains in February 1974. Previous manifestations of cystic fibrosis included dyspnoea at rest, recurrent pneumonia, and chronic diarrhoea. Physical examination revealed a blood pressure of $110 / 80 \mathrm{mmHg}$, pulse 80 , respirations 24 , and temperature $37 \cdot 4^{\circ} \mathrm{C}$. There was marked clubbing of toes and fingers and bilateral knee and ankle tenderness. Joint effusions were not found. Examination of the chest revealed bilateral rhonchi and basal crepitations. The rest of the examination was normal. The sweat chloride was $117 \mathrm{mEq} / 1$. Arterial blood gases while breathing ambient air were pH 7.39, $\mathrm{PCO}_{2}$ $48 \mathrm{mmHg}$, and $\mathrm{Po}_{2} 38 \mathrm{mmHg}$. Pulmonary function tests showed a severe obstructive defect. An electrocardiogram revealed right axis deviation and right atrial and right ventricular enlargement. The chest radiograph showed bilateral interstitial infiltrates, and radiographs of the long bones revealed periosteal elevation and new bone formation over both tibiae. After acetominophen and indomethacin therapy for three weeks the knee and ankle pains disappeared and have not recurred.

\section{DISCUSSION}

The syndrome of hypertrophic osteoarthropathy was described by Bamberger (1889) and Marie (1890). Subsequently, hypertrophic osteoarthropathy has been reported in association with a wide variety of diseases, including neoplasms of the lungs, oesophagus, thymus, and stomach, and intrathoracic Hodgkin's disease (Fischer, Singer, and Feldman, 1964; Shapiro and Zvaifler, 1973). In the pre-antibiotic era, hypertrophic osteoarthropathy was commonly observed in individuals with tuberculosis, bronchiectasis, and empyema (Fischer et al., 1964); Hammarsten and O'Leary, 1957). It has also been reported in patients with inflammatory bowel disease, hepatic cirrhosis, cyanotic congenital heart disease, bacterial endocarditis, and hyperthyroidism (Trever, 1958; Fischer et al., 1964; Stanley and Woodgate, 1971).
However, hypertrophic osteoarthropathy com $-\frac{\overrightarrow{\vec{S}}}{\vec{\theta}}$ plicating cystic fibrosis has not been recognized? widely.

Grossman, Denning, and Baker (1964) described $\frac{\bar{\omega}}{\overparen{\Phi}}$ the occurrence of symptomatic hypertrophic $\stackrel{\Phi}{ }$ osteoarthropathy in two children (aged 9 and 12) with cystic fibrosis. In their series, three otherpatients with cystic fibrosis had clubbing andradiographic evidence of osteoarthropathy with- $\vec{\omega}$ out bone or joint pains. All our patients developed symptomatic hypertrophic osteoarthropathy as $x$ adults. A review of the literature did not reveal ${ }_{a}^{\omega}$ any reference to hypertrophic osteoarthropathy incr association with cystic fibrosis in adults.

The aetiology of hypertrophic osteoarthro-o pathy has not been proven. However, a number? of disease states has been associated with hyper- $\vec{O}$ trophic osteoarthropathy, including pulmonary? diseases (Hammarsten and O'Leary, 1957; Fischero et al., 1964). Each of the patients reported by Grossman and all of our patients with cystic $\vec{e}$ fibrosis had advanced lung disease. Chronic liverò disease has also been frequently associated with hypertrophic osteoarthropathy (Trever, 1958; Fischer et al., 1964). Histological evidence of biliary cirrhosis has been reported in $5 \%$ of children and in $20 \%$ of adults with cystic fibrosis. $\stackrel{\circ}{\Phi}$ Although none of Grossman's five patients had $\stackrel{\varrho}{\vec{P}}$ clinical evidence of liver disease, one had cirrhosiso at necropsy. One of our patients (patient 1) had clinical evidence of liver disease manifested by hepatosplenomegaly and oesophageal varices. Diseases causing chronic diarrhoea, such as regional enteritis and ulcerative colitis, have alsow been reported in association with hypertrophic osteoarthropathy (Fischer et al., 1964). All three of our patients and two of Grossman's hadi chronic diarrhoea. Thus, pulmonary, hepatic, andङ gastrointestinal disease may be related to theo development of hypertrophic osteoarthropathy in? cystic fibrosis.

All three subjects in the present series ex perienced improvement or disappearance of symptoms after analgesic and anti-inflammatory $\mathcal{O}^{\circ}$ therapy and remained free of symptoms during follow-up period of 10 to 14 months. Howevero the radiographic bone abnormalities persist and the long-term course of hypertrophic osteo $\frac{\bar{D}}{\mathrm{D}}$ arthropathy in patients with cystic fibrosis is unknown.

Since hypertrophic pulmonary osteoarthropathy has not been recognized widely in association with? cystic fibrosis, the true incidence of this com $\mathscr{D}$ plication is not known. With early diagnosis an 
improved maintenance therapy many patients with cystic fibrosis survive to adulthood (Coates, 1966; Goodman, 1967), and it is likely that in the future hypertrophic osteoarthropathy will be diagnosed with increasing frequency among adults with cystic fibrosis. The cases in this series suggest that in all patients with cystic fibrosis in whom bone or joint pains develop the diagnosis of hypertrophic osteoarthropathy must be considered and long bone radiographs obtained to make the diagnosis.

\section{REFERENCES}

Bamberger, E. (1889). In Protokoll der k.k. Gesellschaft der Aerzte in Wien. Wiener Klinische Wochenschrift, 2, 226.

Coates, E. O., Jr. (1966). Characteristics of cystic fibrosis in adults. Diseases of the Chest, 49, 195.

Fischer, D. S., Singer, D. H., and Feldman, S. M. (1964). Clubbing: a review with emphasis on hereditary acropachy. Medicine, 43, 459.

Goodman, D. H. (1967). Adult mucoviscidosis. Annals of Allergy, 25, 224.

Grossman, H., Denning, C. R., and Baker, D. H. (1964). Hypertrophic osteoarthropathy in cystic fibrosis. American Journal of Diseases of Children, 107, 1.

Hammarsten, J. F. and O'Leary, J. (1957). The features and significance of hypertrophic osteoarthropathy. Archives of Internal Medicine, 99, 431.

Jones, J. D., Steige, H., and Logan, G. B. (1970) Variations of sweat sodium values in children and adults with cystic fibrosis and other diseases. Mayo Clinic Proceedings, 45, 768.

Kopel, F. B. (1972). Gastrointestinal manifestations of cystic fibrosis. Gastroenterology, 62, 483.

Marie, P. (1890). De l'ostéoarthropathie hypertrophiante pneumonique. Revue de Médecine, 10, 1.

Shapiro, R. F. and Zvaifler, N. J. (1973). Concurrent intrathoracic Hodgkin's disease and hypertrophic osteoarthropathy. Chest, 63, 912.

Stanley, N. N. and Woodgate, D. J. (1971). The circulation, the lung, and finger clubbing in hepatic cirrhosis. British Heart Journal, 33, 469.

Trever, R. W. (1958). Hypertrophic osteoarthropathy in association with congenital cyanotic heart disease. Annals of Internal Medicine, 48, 660.

Requests for reprints to: Dr. R. A. Matthay, Yale Lung Research Center, 333 Cedar Street, New Haven, Connecticut 06510, USA. 